\title{
Clinical significance of serum total oxidant/ antioxidant status in patients with operable and advanced gastric cancer
}

This article was published in the following Dove Press journal:

OncoTargets and Therapy

\author{
Xue-Fang $\mathrm{Du}^{\prime}$ \\ Li-Li Zhang' \\ De-Zhong Zhang ${ }^{2}$ \\ Lu Yang' \\ Ying-Ying Fan' \\ Shu-Ping Dong' \\ 'Department of Gastroenterology, \\ First Affiliated Hospital of Xin-Xiang \\ Medical University, Henan, People's \\ Republic of China; ${ }^{2}$ Gastrointestinal \\ Surgery, The First Affiliated Hospital \\ of Xin-Xiang Medical University, \\ Henan, People's Republic of China
}

Correspondence: Xue-Fang Du Department of Gastroenterology, First Affiliated Hospital of XinXiang Medical University, No. 88 Jiankang Road, Henan 453100,

People's Republic of China

Tel +863734402120

Fax +863734402120

Email duxuefang880@126.com
Purpose: Oxidative stress was significantly associated with the development of malignancies. The purpose of this study was to evaluate the significance of serum total oxidant/antioxidant status in operable advanced gastric cancer patients.

Materials and methods: A total of 284 patients who underwent curative resection for primary stage III gastric cancer were enrolled. Total oxidant status, total antioxidant status, and oxidative stress index (OSI) were evaluated within 24 hours before surgery, and compared with 120 healthy donors. The correlation between the OSI and survival outcome was analyzed by the Kaplan-Meier method with log-rank test and Cox's regression methods, respectively.

Results: Mean OSI of gastric cancer patients was higher than healthy controls $(1.41 \pm 0.96 \mathrm{vs}$ $0.78 \pm 0.42, P<0.001)$. All patients were stratified into two groups using the optimal cutoff value (1.42) of OSI using a sensitivity of $94.1 \%$ and a specificity of $64.0 \%$ as optimal conditions from receiver operating curve analysis. Patients with an OSI $\geq 1.42$ had poorer mean overall survival (45.6 vs 29.8 months, $P=0.022$ ) and mean recurrence-free survival (43.3 vs 28.1 months, $P=0.011$ ) than patients with an OSI $<1.42$ in univariate analysis, and OSI was also confirmed as an independent predictor for survival for gastric cancer in multivariate analysis (hazard ratio, $0.541 ; 95 \%$ CI: $0.127-1.102 ; P=0.01)$.

Conclusion: Preoperative OSI can be considered as an independent prognostic factor for operable and advanced gastric cancer.

Keywords: oxidative stress index, survival, gastric cancer

\section{Introduction}

Gastric cancer is one of most prevalent cancers worldwide, and also accounts for the second most frequent malignancy and the third leading cause of cancer-related death in People's Republic of China. ${ }^{1,2}$ Despite the great improvement in early diagnosis and comprehensive treatments, the long-term outcomes of gastric cancer patients are far from satisfying, with a 5-year survival rate of $20 \%-30 \% .^{3-5}$ Surgery remains the only curative treatment for localized gastric cancer. ${ }^{6}$ However, $50 \%-90 \%$ of the patients with advanced and localized gastric cancer still had poor postoperative prognosis due to local recurrence or distant metastasis. ${ }^{7-9}$ For such a patient population, preoperative risk stratification may be useful to guide comprehensive treatments and improve the short- and long-term clinical outcome. Some prognostic biomarkers which can be obtained easily and inexpensively in clinical practice have attracted the attention of many physicians, and an increasing number of studies have been conducted..$^{7,10,11}$ It has been revealed that oxidative stress plays a crucial role in promoting tumor proliferation, invasion, and metastases. ${ }^{12,13}$ However, prospective studies investigating hereby accept the Terms. Non-commercial uses of the work are permitted without any furcher permission from Dove Medical Press Limited, provided the work is properly attributed. For permission for commercial use of this work, please see paragraphs 4.2 and 5 of our Terms (https://www.dovepress.com/terms.php). 
the association between development of gastric cancer and parameters of oxidative stress are scarce.

Oxidative stress participates in macromolecular oxidative damage, results in tissue protein denaturation, DNA damage, and lipid peroxidation, and interferes with normal metabolic activity, thus inducing the occurrence and/or development of cancer. ${ }^{14,15}$ Reactive oxygen species (ROS), as the main active oxides mediating oxidative stress, are involved in the occurrence and development of cancer through induction of DNA damage and genetic mutations, inhibition of apoptosis, and promotion of the proliferation, invasion, and metastasis of tumor cells. ${ }^{16,17}$ Finding biomarkers inflecting the oxidative stress status may be helpful for prognosis evaluation and risk stratification in gastric cancer patients.

Therefore, the total oxidant status (TOS) is usually used to evaluate the overall oxidation state of the body, while the total antioxidant status (TAS) is applied to measure the overall antioxidant status. ${ }^{18,19}$ Furthermore, the oxidative stress index (OSI), the ratio of TOS to TAS, is considered as a more precise biomarker reflecting oxidative stress. OSI can reflect imbalance between oxidation and antioxidants through comprehensive measurement of TAS and TOS. ${ }^{20}$ However, there was no data regarding the evaluation of TOS, TAS, and OSI in patients with gastric cancer. In this study, we tried to evaluate preoperative serum total oxidant/antioxidant status in gastric cancer patients though TOS, TAS, and OSI measurements, and analyze the clinical significance of such an indicator in gastric cancer patients who underwent curative resection.

\section{Materials and methods}

\section{Patients}

Data of 284 consecutive patients who underwent curative resection for histologically confirmed stage III gastric cancer between June 1, 2010, and June 1, 2016, at the Department of Gastroenterology in the First Affiliated Hospital of XinXiang Medical University were prospectively collected in a preplanned database. According to the planed inclusion criteria, only histologically and clinically confirmed stage III gastric cancer patients, patients aged $>18$ years, and those with a life expectancy more than 6 months were enrolled. Patients with preoperative severe comorbidity, such as ischemic diseases, severe cardiac or neurological disorders, or other kind of malignant disease, chronic inflammatory disease, acute and chronic infective disease, and immunosuppressive disorders, were excluded from the study. Likewise, patients who received preoperative adjuvant treatments and chemotherapy also were excluded. According to the 2015 NCCN Clinical
Practice Guidelines in Oncology, all gastric cancer patients received a standard curative resection, and then were treated with postoperative standard chemotherapeutic regimens based on histopathological and clinical characteristics of tumor, including epirubicin, cisplatin, and 5-fluorouracil or docetaxel, cisplatin, and 5-fluorouracil. A control group that consisted of 112 age- and sex-matched healthy volunteers was enrolled. Written informed consent was obtained from individual patients and subjects. This study was approved by the Ethics Committee of the First Affiliated Hospital of Xin-Xiang Medical University.

\section{Clinical assessment}

Demographic and clinicopathological characteristics of all the patients were collected by one physician, and further checked by another attending surgeon; the data included gender, age, tumor site and size, tumor invasion depth, lymph node status, TNM stage, and pathological differentiation. The histopathological and clinical staging evaluation of tumor was based on postoperative histopathological examination of specimens and clinical assessment, according to the seventh edition American Joint Committee on Cancer TNM classification. Outcome was evaluated as overall survival (OS) and recurrence-free survival (RFS). OS was accurately defined as the duration from date of surgery to death, whereas RFS was calculated as the time from surgery to tumor recurrence. All patients were followed up at regular intervals through outpatient visits with physical examination and laboratory and radiographic studies every 3 months for the first 2 years, every 6 months for the next 3 years, and once annually thereafter. Gastroscopy, and enhanced abdominal computed tomography or magnetic resonance imaging scans were performed generally every 12 months. Clinical follow-up lasted from the date of surgery to either the time of death or February 2017.

\section{Measurement of TOS, TAS, and OSI}

The TOS and TAS level were measured according to Erel's methods. ${ }^{18,19}$ Briefly, approximately $5 \mathrm{~mL}$ peripheral venous blood samples of gastric cancer patients and healthy controls were obtained and stored in a blood collection tube (BD Vacutainer, Becton Dickinson, Franklin Lakes, NJ, USA) on the day before the surgery. All study participants fasted for at least 12 hours before blood collection. After centrifugation, the sera were decanted and measured immediately using commercially available test kits (Rel Assay Diagnostics kit; Mega Tip, Gaziantep, Turkey) according to the manufacturer's instructions and using their reagents and 
equipment. The results of the TAS are expressed as mmol Trolox Eq/L whereas the results of the TOS are expressed as $\mu \mathrm{mol} \mathrm{H}_{2} \mathrm{O}_{2} \mathrm{Eq} / \mathrm{L}$. OSI values were calculated as follows: OSI (arbitrary unit $)=\operatorname{TOS}\left(\mu \mathrm{mol} \mathrm{H}_{2} \mathrm{O}_{2} \mathrm{Eq} / \mathrm{L}\right) / \mathrm{TAS}(\mu \mathrm{mol}$ Trolox Eq/L) $\times 100$.

\section{Statistical analysis}

All statistical analyses were carried out with SPSS version 20.0 (IBM Corporation, Armonk, NY, USA). All tests were two-sided, and a $P$-value $<0.05$ was considered statistically significant. Data for categorical variables were expressed as percentage and for continuous variables as mean $\pm \mathrm{SD}$. The optimal cutoff value of the OSI predicting survival was determined based on receiver operating characteristic (ROC) curve analysis. The $\chi^{2}$ test or Fisher's exact test was used to analyze categorical variables, whereas continuous variables in normal distribution were analyzed by independent Student's $t$-test, or by Mann-Whitney $U$-test for abnormal distribution data. The OS and RFS and survival curve were based on Kaplan-Meier analyses by using the log-rank test. The Cox regression model was used to assess the hazard ratio (HR) and multivariate analysis.

\section{Results}

\section{Patient}

All baseline demographic and clinicopathologic data of the 284 patients with stage III gastric cancer are summarized in Table 1. Among gastric cancer patients, the average age was 58.6 \pm 7.6 years, and $196(69.0 \%)$ patients were males. The most frequent site of tumor formation was the stomach body, which accounted for 140 of 274 patients (51.1\%). There were 95 patients identified with T2 tumor stage, and 189 patients with T3 or T4 tumor stage. Histopathological examination revealed that 164 patients presented with well/moderately differentiated adenocarcinomas, while 120 patients had poorly differentiated tumors. The number of TNM stage IIIA, stage IIIB, and stage IIIC patients was $32(11.7 \%), 94(34.3 \%)$, and $148(54.0 \%)$, respectively. Moreover, there was no statistically significant association between the OSI and clinicopathologic characteristics including age and gender of patients, tumor size, histological differentiation type, $\mathrm{T}$ stage, lymph node involvement, and recurrent type, except the TAS (Table 1).

\section{Serum TOS,TAS, and OSI levels in patients with gastric cancer}

The mean TOS level from 274 patients with stage III gastric cancer was $23.16 \pm 13.76$, which was significantly higher than
Table I Correlation between the OSI and clinicopathologic characteristics in patients with gastric cancer

\begin{tabular}{|c|c|c|c|}
\hline \multirow[t]{2}{*}{ Characteristic } & \multicolumn{2}{|l|}{ OSI } & \multirow[t]{2}{*}{$P$-value } \\
\hline & $\geq 1.42(n=193)$ & $<1.42(n=91)$ & \\
\hline Age (years) & & & $0.97 \mathrm{I}$ \\
\hline$\geq 60$ & 95 & 45 & \\
\hline$<60$ & 98 & 46 & \\
\hline Gender & & & 0.546 \\
\hline Male & $|3|$ & 65 & \\
\hline Female & 62 & 26 & \\
\hline BMI $\left(\mathrm{kg} / \mathrm{m}^{2}\right)$ & $23.2 \pm 6.1$ & $23.6 \pm 7.8$ & 0.638 \\
\hline CRP $(\mathrm{mg} / \mathrm{L})$ & $112.4 \pm 84.5$ & $128.5 \pm 78.4$ & 0.136 \\
\hline TAS ( mmol Trolox Eq/L) & $24.6 \pm 16.2$ & $20.4 \pm 12.2$ & 0.029 \\
\hline $\operatorname{TOS}\left(\mu \mathrm{mol} \mathrm{H} \mathrm{O}_{2} \mathrm{Eq} / \mathrm{L}\right)$ & $1.4 \pm 0.6$ & $1.5 \pm 0.8$ & 0.242 \\
\hline Tumor site & & & 0.420 \\
\hline Gastric cardia & 42 & 25 & \\
\hline Gastric body & 100 & 40 & \\
\hline Gastric antrum & 51 & 26 & \\
\hline Tumor size $(\mathrm{cm})$ & & & 0.957 \\
\hline$\geq 5$ & 60 & 28 & \\
\hline$<5$ & 133 & 63 & \\
\hline Tumor invasion depth & & & $0.70 \mathrm{I}$ \\
\hline $\mathrm{T} 2$ & 62 & 33 & \\
\hline $\mathrm{T} 3+\mathrm{T} 4$ & $|3|$ & 58 & \\
\hline Lymph node involvement & & & 0.643 \\
\hline No & 99 & 44 & \\
\hline $\mathrm{NI}$ & 94 & 47 & \\
\hline Pathological differentiation & & & 0.690 \\
\hline Well/moderate & 113 & 51 & \\
\hline Poor & 80 & 40 & \\
\hline Recurrence type & & & 0.334 \\
\hline Local relapse & 65 & 36 & \\
\hline Metastasis & 128 & 55 & \\
\hline
\end{tabular}

Abbreviations: BMI, body mass index; CRP, C-reactive protein; OSI, oxidative stress index; TAS, total antioxidant status; TOS, total oxidant status.

that of healthy controls $(\mathrm{n}=120 ; 14.23 \pm 10.08 ; P<0.001)$. However, the mean TAS of gastric cancer patients was lower than healthy controls $(1.52 \pm 0.66$ vs $1.78 \pm 1.31, P=0.01)$. The mean OSI of gastric cancer patients was also higher than that of controls $(1.41 \pm 0.96$ vs $0.78 \pm 0.42, P<0.001)$, as can be seen from Figure 1.

\section{Prognostic significance of OSI for gastric cancer}

The cutoff value for the OSI for predicting survival of gastric cancer patients in the ROC analysis was 1.42 , with a sensitivity of $94.1 \%$ and a specificity of $64.0 \%$. The area under curve was 0.793 with a $95 \%$ confidence interval $(95 \% \mathrm{CI})$ between 0.676 and $0.910, P<0.001$ (Figure 2).

The median follow-up duration was 25.6 months (6.5-76.5 months). Finally, 173 (63.1\%) out of all 274 patients had died, including $44(51.2 \%)$ in 86 patients 
A

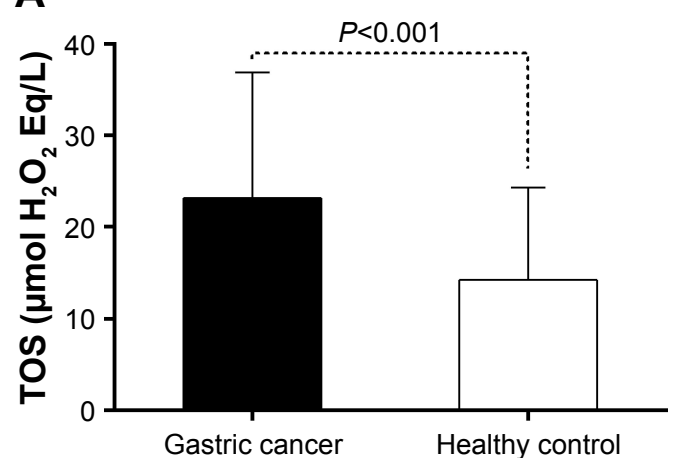

B

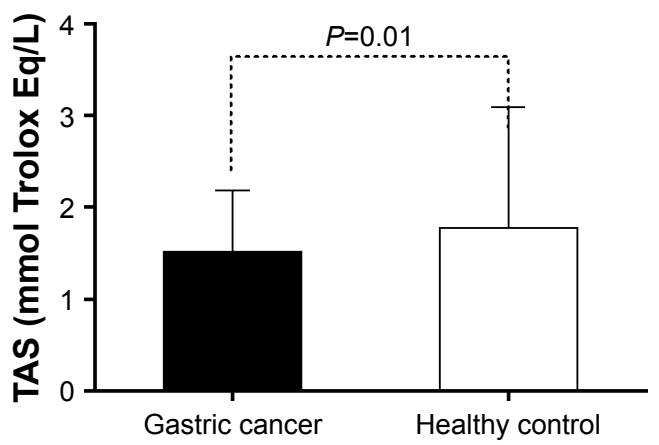

C

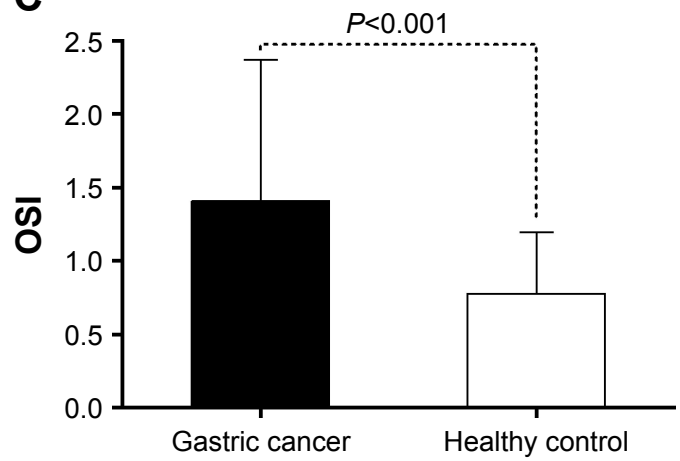

Figure I Evaluation of TOS/TAS status in patients with advanced gastric cancer.

Notes: (A) Shows the results of the difference of TOS between patients with gastric cancer $(n=284)$ and healthy controls ( $n=120)$ (mean TOS in gastric cancer, 23. I6 \pm 13.76 ; in healthy subjects, $14.23 \pm 10.08, P<0.00 I$ ). (B) Shows the mean TAS of gastric cancer patients, which was lower than healthy controls $(I .52 \pm 0.66$ vs $I .78 \pm I .3 I, P=0.0 \mathrm{I})$. (C) Shows that mean OSI of gastric cancer patients was also higher than that of controls $(I .4 I \pm 0.96$ vs $0.78 \pm 0.42, P<0.00 \mathrm{I})$.

Abbreviations: OSI, oxidative stress index; TAS, total antioxidant status; TOS, total oxidant status.

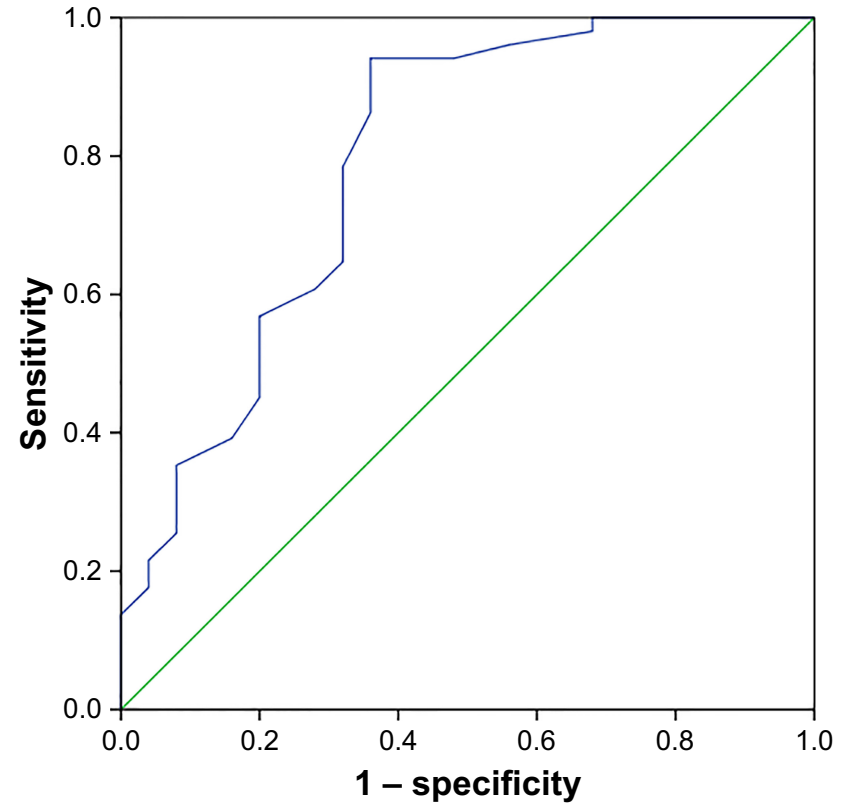

Figure 2 ROC for OSI predicting survival of gastric cancer.

Note: The cutoff value of OSI was I.42, the AUC was 0.7394 with a $95 \% \mathrm{Cl}$ for the area between 0.672 and $0.916, P<0.001$.

Abbreviations: AUC, area under the curve; ROC, receiver operating characteristic curve; OSI, oxidative stress index. with an OSI $<1.42$ and $129(68.6 \%)$ out of 188 patients with an OSI $\geq 1.42$, respectively. One hundred and thirtyfour $(71.3 \%)$ in group of 188 patients with an OSI $\geq 1.42$ had tumor relapse, while $47(54.7 \%)$ in 86 patients with an OSI $<1.42$ suffered recurrence. Kaplan-Meier univariate survival analysis showed lymph node involvement, histological differentiation type, and preoperative OSI were related to postoperative survival of stage III gastric cancer patients. Among these prognostic factors, the mean OS of patients with a preoperative OSI $<1.42$ was 45.6 months, which was significantly higher than the 29.84 months of those with an OSI $\geq 1.42$ ( $P=0.022$ ) (Table 2, Figure 3). Furthermore, we obtained a similar result in the multivariate analysis for OS (HR, 0.541; 95\% CI: 0.127-1.102; $P=0.01$ ) (Table 2). Otherwise, in univariate analysis of RFS, patients with a high OSI also had shorter mean RFS than patients with a low OSI (43.3 vs 28.1 months, $P=0.011$ ), and the OSI was also confirmed as a significant independent predictor for RFS in multivariate analysis (HR, 0.871; 95\% CI: 0.294-1.662; $P=0.023$ ) (Table 3, Figure 3). 
Table 2 Univariate and multivariate analyses of the prognostic factors of OS for stage III gastric cancer

\begin{tabular}{|c|c|c|c|c|c|c|}
\hline \multirow[t]{2}{*}{ Characteristics } & \multicolumn{3}{|c|}{ Univariate } & \multicolumn{3}{|c|}{ Multivariate } \\
\hline & $\mathbf{N}$ & $\begin{array}{l}\text { MS } \\
\text { (months) }\end{array}$ & $P$-value & OR & $95 \% \mathrm{Cl}$ & $P$-value \\
\hline Age (years) & & & 0.312 & & & \\
\hline$\geq 60$ & 140 & 32.8 & & & & \\
\hline$<60$ & 144 & 31.7 & & & & \\
\hline Gender & & & 0.942 & & & \\
\hline Male & 196 & 26.7 & & & & \\
\hline Female & 88 & 30.4 & & & & \\
\hline Tumor site & & & 0.831 & & & \\
\hline Gastric cardia & 67 & 29.2 & & & & \\
\hline Gastric body & 140 & 27.2 & & & & \\
\hline Gastric antrum & 77 & 28.3 & & & & \\
\hline Tumor size $(\mathrm{cm})$ & & & 0.082 & & & \\
\hline$\geq 5$ & 88 & 27.5 & & & & \\
\hline$<5$ & 196 & 36.2 & & & & \\
\hline Tumor invasion depth & & & 0.351 & & & \\
\hline $\mathrm{T} 2$ & 95 & 32.5 & & & & \\
\hline $\mathrm{T} 3+\mathrm{T} 4$ & 189 & 22.7 & & & & \\
\hline Lymph node involvement & & & 0.011 & 2.141 & $0.723-3.214$ & 0.012 \\
\hline No & 143 & 38.3 & & & & \\
\hline $\mathrm{NI}$ & $14 \mid$ & 24 & & & & \\
\hline Pathological differentiation & & & 0.032 & 1.371 & $0.82 \mathrm{I}-2.765$ & 0.021 \\
\hline Well/moderate & 164 & 32.3 & & & & \\
\hline Poor & 120 & 24.2 & & & & \\
\hline OSI & & & 0.022 & $0.54 I$ & $0.127-1.102$ & 0.010 \\
\hline$<\mathrm{I} .42$ & 91 & 45.6 & & & & \\
\hline$\geq 1.42$ & 193 & 29.8 & & & & \\
\hline
\end{tabular}

Abbreviations: $\mathrm{Cl}$, confidence interval; MS, median survival; OR, odds ratio; OS, overall survival; OSI, oxidative stress index.
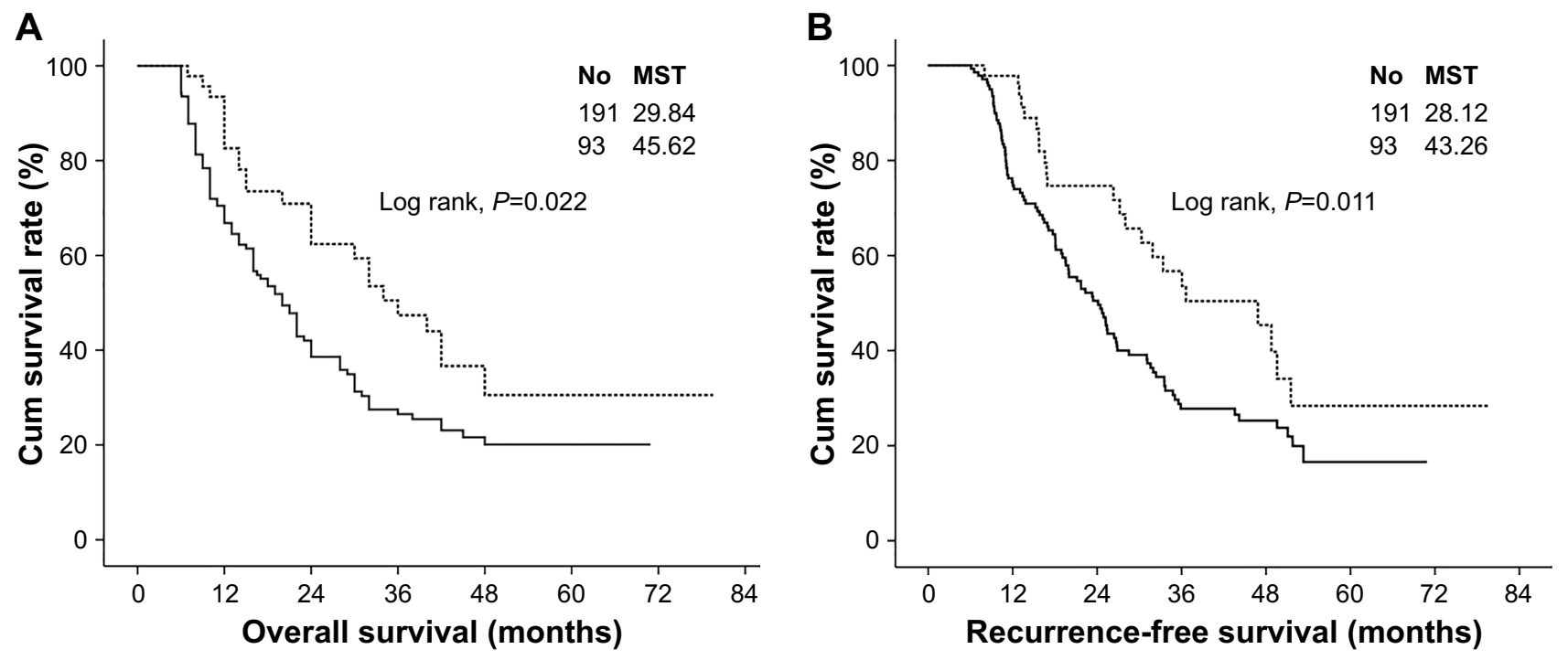

$\neg \mathrm{OSI} \geq 1.42 \quad$..: OSI $<1.42$

Figure 3 Prognostic significance of serum OSI for stage III gastric cancer.

Notes: (A) Left panel shows the association between OSI and OS (mean OS in OSI <I.42, 45.62 months; in OSI $\geq 1.42,29.84$ months, $P=0.022$ ). (B) Right panel shows the association between OSI and RFS (mean RFS in OSI <I.42, 43.26 months; in OSI $\geq 1.42,28.12$ months, $P=0.01 \mathrm{I}$ ).

Abbreviations: OS, overall survival; OSI, oxidative stress index; RFS, recurrence-free survival; MST, mean survival time; Cum, cumulative. 
Table 3 Univariate and multivariate analyses of the prognostic factors of RFS for stage III gastric cancer

\begin{tabular}{|c|c|c|c|c|c|c|}
\hline \multirow[t]{2}{*}{ Characteristics } & \multicolumn{3}{|c|}{ Univariate } & \multicolumn{3}{|c|}{ Multivariate } \\
\hline & $\mathbf{N}$ & $\begin{array}{l}\text { MS } \\
\text { (months) }\end{array}$ & $P$-value & OR & $95 \% \mathrm{Cl}$ & $P$-value \\
\hline Age (years) & & & 0.731 & & & \\
\hline$\geq 60$ & 140 & 26.8 & & & & \\
\hline$<60$ & 144 & 26.4 & & & & \\
\hline Gender & & & 0.923 & & & \\
\hline Male & 196 & 24.5 & & & & \\
\hline Female & 88 & 28.4 & & & & \\
\hline Tumor site & & & 0.312 & & & \\
\hline Gastric cardia & 67 & 26.2 & & & & \\
\hline Gastric body & 140 & 26.1 & & & & \\
\hline Gastric antrum & 77 & 25.2 & & & & \\
\hline Tumor size $(\mathrm{cm})$ & & & 0.232 & & & \\
\hline$\geq 5$ & 88 & 26.3 & & & & \\
\hline$<5$ & 196 & 27.8 & & & & \\
\hline Tumor invasion depth & & & 0.451 & & & \\
\hline $\mathrm{T} 2$ & 95 & 27.4 & & & & \\
\hline $\mathrm{T} 3+\mathrm{T} 4$ & 189 & 24.5 & & & & \\
\hline Lymph node involvement & & & 0.032 & 1.731 & $0.42 I-2.212$ & 0.010 \\
\hline No & 143 & 36.2 & & & & \\
\hline $\mathrm{NI}$ & 141 & 21.3 & & & & \\
\hline Pathological differentiation & & & 0.012 & & & \\
\hline Well/moderate & 164 & 31.1 & & & & \\
\hline Poor & 120 & 21.1 & & & & \\
\hline OSI & & & 0.011 & 0.871 & $0.294-1.662$ & 0.023 \\
\hline$<\mathrm{I} .42$ & 91 & 43.3 & & & & \\
\hline$\geq 1.42$ & 193 & 28.1 & & & & \\
\hline
\end{tabular}

Abbreviations: $\mathrm{Cl}$, confidence interval; MS, median survival; RFS, recurrent-free survival; OR, odds ratio; OSI, oxidative stress index.

A multivariate analysis included age and gender of patients, tumor size, lymph node involvement, histological differentiation type, and preoperative OSI into the Cox regression model to determine independent prognostic biomarkers for stage III gastric cancer. The result showed that OSI (HR, 0.541; 95\% CI: 0.127-1.102; $P=0.01$ ), lymph node involvement (HR, 2.141; 95\% CI: 0.723-3.214; $P=0.012$ ) and pathological differentiation (HR, 1.371; 95\% CI: $0.821-2.765 ; P=0.021)$ were the independent prognostic factors for OS (Table 2). Furthermore, OSI (HR, 0.871; 95\% CI: $0.294-1.662 ; P=0.023)$ and lymph node involvement (HR, 1.731; 95\% CI: 0.421-2.212; $P=0.002)$ were the independent prognostic factors for RFS (Table 3).

\section{Correlation of OSI with prognosis of stage IIIA, IIIB, and IIIC gastric cancer patients}

In setting of fewer stage IIIA cases, we combine patients with stage IIIA and IIIB into one group $(n=126)$, with the other group consisting of stage IIIC patients $(n=148)$. For stage IIIA and IIIB group, the mean OS of patients with an OSI $\geq 1.42$ was significantly poorer than that of patients with an OSI $<1.42$ (41.0 vs 36.6 months, $P=0.039$ ), and the RFS analysis showed nonsignificant results (41.0 vs 34.4 months, $P=0.296)$. For stage IIIC patients, patients with an OSI $<1.42$ had better mean OS (42.4 vs 24.7 months, $P=0.004)$ and mean RFS (38.3 vs 21.9 months, $P=0.008$ ), compared to patients with an OSI $\geq 1.42$ (Figure $4 \mathrm{~A}-\mathrm{D})$.

\section{Discussion}

In this study, we prospectively evaluated the preoperative OSI, TAS, and TOS of patients with stage III gastric cancer and found that gastric cancer patients had a significant higher TOS and OSI level and lower TAS level than healthy controls, and further found that OSI was a useful and independent predictive biomarker for survival in patients with advanced gastric cancer by univariate and multivariate analysis. Therefore, we confirmed that the OSI can be evaluated for optimal risk stratification of individual patients with gastric cancer and can serve as a biomarker for predicting postoperative prognosis of patients with advanced gastric cancer.

Oxidative stress has important roles in the occurrence, development, and metastasis of cancer. ${ }^{21-23}$ Oxidative stress induces production of ROS, and then results in protein 

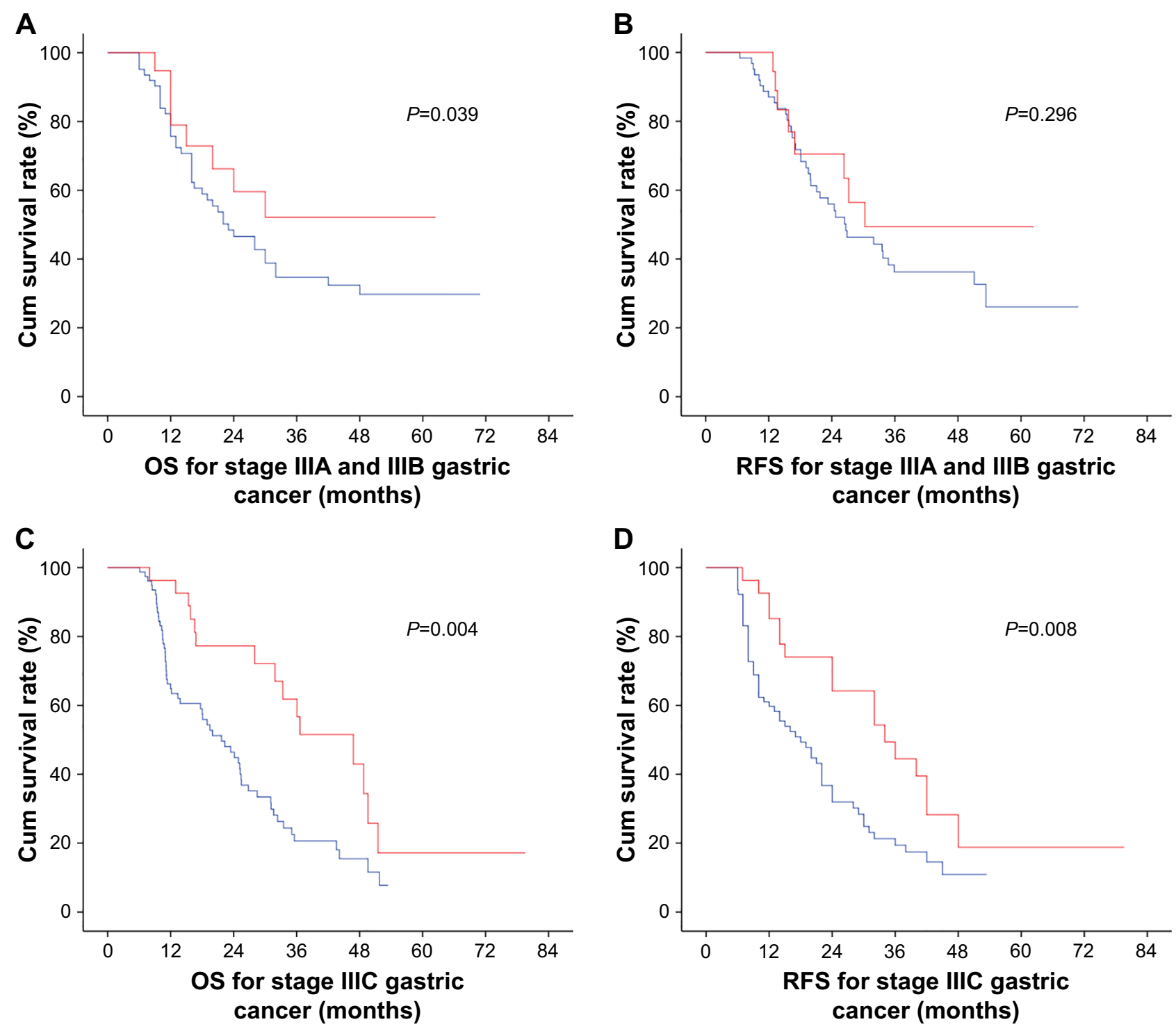

$\neg \mathrm{OSI} \geq 1.42 \neg \mathrm{OSI}<1.42$

Figure 4 Survivability based on TNM stage.

Notes: Panel (A) and panel (B) show that there was a statistically significant correlation between OSI and OS, but not RFS of stage IIIA and IIIB gastric cancer patients. Panels (C and D) shows there was a significant association between OSI and OS and RFS of stage IIIC cancer patients.

Abbreviations: OS, overall survival; OSI, oxidative stress index; RFS, recurrence-free survival; Cum, cumulative.

denaturation or DNA damage, thus inhibiting normal physiological functions of various intracellular components, and finally leading to cancer development. In detail, ROS can oxidize guanine in DNA and RNA to form 8-hydroxyguanine (8-OHG) ${ }^{24}$ which potentially introduces missense mutations. ${ }^{25}$ Moreover, prior studies have found that there was a strong correlation between the formation of 8-OHG and carcinogenesis. ${ }^{26,27}$ Otherwise, ROS widely participates in human tumorigenesis by affecting the major intracellular signaling pathways, such as MAP kinase and PI3K/Akt pathways. ${ }^{28,29}$ It has been revealed that several biomarkers directly reflecting oxidative stress status were significantly associated with cancer, such as TOS, TAS, OSI, and ischemia-modified albumin. ${ }^{30-33}$ In this study, we confirmed that TOS and OSI levels in gastric cancer patients were higher than healthy subjects, further suggesting the important roles of oxidative stress in the development of gastric cancer.

Oxidative stress can promote several pathways that enable tumor progression and aggressiveness by regulation of proliferation, apoptosis, and invasion of tumor cells. ${ }^{34,35}$ Furthermore, the severity of tissue inflammation and oxidative stress is directly associated with the prognosis of cancer. ${ }^{36}$ Thus, OSI, as a biomarker directly reflecting imbalance 
between oxidation and antioxidant oxidative stress has been confirmed as a potential prognostic biomarker in other diseases involved with oxidative stress. ${ }^{37,38}$ In current study, we first explored prognostic significance of preoperative OSI in patients with stage III gastric cancer and found that OSI was significantly associated with OS and RFS of patients with gastric cancer.

Furthermore, in this study, we first confirmed that the OSI was an independent biomarker for prognosis in gastric cancer patients compared with other classical predictors including lymph node involvement and pathological differentiation. At the end of study, mortality rate was higher for patients with high OSI than those with lower levels, so physicians should be aware of the risk of patients with a high OSI and provide more proactive intervention to decrease OSI. However, OSI is not a direct contributor to poor outcomes, but a marker of severe oxidative stress. Targeting the original abnormal process might be a reasonable strategy to decrease OSI, such as mitochondrial targeted therapy. ${ }^{39}$

Several limitations may influence the interpretation of the results of this study. One limitation is that it is a single center study. A large-scale, multicenter, prospective study should be conducted to confirm long-term results and obtain more definite evidence. Furthermore, we analyzed the cutoff levels of the OSI though ROC curve in a small cohort, which may imply some overestimation. ${ }^{40}$ Thus, the results of this study may not be comparable with those of other studies. A metaanalysis including various OSI validation studies may be required to confirm more definite cutoff values for the OSI.

\section{Conclusion}

Our study confirmed that patients with advanced gastric cancer have higher TOS and OSI. More importantly, we found that preoperative OSI was an independent prognostic factor for operable and advanced gastric cancer.

\section{Disclosure}

The authors report no conflicts of interest in this work.

\section{References}

1. Siegel RL, Miller KD, Jemal A. Cancer statistics, 2016. CA Cancer J Clin. 2016;66(1):7-30.

2. Chen W. Cancer statistics: updated cancer burden in China. Chin J Cancer Res. 2015;27(1):1.

3. Dittmar Y, Schüle S, Koch A, Rauchfuss F, Scheuerlein H, Settmacher U. Predictive factors for survival and recurrence rate in patients with nodenegative gastric cancer - a European single-centre experience. Langenbecks Arch Surg. 2015;400(1):27-35.

4. Siewert JR, Böttcher K, Stein HJ, Roder JD. Relevant prognostic factors in gastric cancer: ten-year results of the German Gastric Cancer Study. Ann Surg. 1998;228(4):449-461.
5. Wang W, Li YF, Sun XW, et al. Prognosis of 980 patients with gastric cancer after surgical resection. Chin J Cancer. 2010;29(11):923-930.

6. Ajani JA, D'Amico TA, Almhanna K, et al. Gastric Cancer, Version 3. 2016, NCCN Clinical Practice Guidelines in Oncology. J Natl Compr Canc Netw. 2016;14(10):1286-1312.

7. Liu X, Sun X, Liu J, et al. Preoperative C-Reactive Protein/Albumin Ratio Predicts Prognosis of Patients after Curative Resection for Gastric Cancer. Transl Oncol. 2015;8(4):339-345.

8. Zhao JZ, Zhang RP, Wang G, et al. Prognosis of patients with recurrence after curative resection of advanced gastric cancer. Zhonghua Wei Chang Wai Ke Za Zhi. 2011;14(2):107-110.

9. An JY, Baik YH, Choi MG, et al. The prognosis of gastric cardia cancer after R0 resection. Am J Surg. 2010;199(6):725-729.

10. Cao Y, Liu H, Zhang H, et al. Decreased expression of Siglec-8 associates with poor prognosis in patients with gastric cancer after surgical resection. Tumour Biol. 2016;37(8):10883-10891.

11. Li P, Ling YH, Zhu CM, et al. Vascular invasion as an independent predictor of poor prognosis in nonmetastatic gastric cancer after curative resection. Int J Clin Exp Pathol. 2015;8(4):3910-3918.

12. Halliwell B. Oxidative stress and cancer: have we moved forward? Biochem J. 2007;401(1):1-11.

13. Gill JG, Piskounova E, Morrison SJ. Cancer, Oxidative Stress, and Metastasis. Cold Spring Harb Symp Quant Biol. 2017;81:163-175.

14. Toyokuni S. Oxidative stress as an iceberg in carcinogenesis and cancer biology. Arch Biochem Biophys. 2016;595:46-49.

15. Prasad S, Gupta SC, Pandey MK, Tyagi AK, Deb L. Oxidative Stress and Cancer: Advances and Challenges. Oxid Med Cell Longev. 2016; 2016:5010423.

16. Pilco-Ferreto N, Calaf GM. Influence of doxorubicin on apoptosis and oxidative stress in breast cancer cell lines. Int J Oncol. 2016; 49(2):753-762.

17. Luo $\mathrm{D}, \mathrm{Xu} Z, \mathrm{Hu} X$, et al. URI prevents potassium dichromate-induced oxidative stress and cell death in gastric cancer cells. Am J Transl Res. 2016;8(12):5399-5409.

18. Erel O. A new automated colorimetric method for measuring total oxidant status. Clin Biochem. 2005;38(12):1103-1111.

19. Erel O. A novel automated direct measurement method for total antioxidant capacity using a new generation, more stable ABTS radical cation. Clin Biochem. 2004;37(4):277-285.

20. Harma M, Harma M, Erel O. Increased oxidative stress in patients with hydatidiform mole. Swiss Med Wkly. 2003;133(41-42):563-566.

21. Lv JC, Wang G, Pan SH, Bai XW, Sun B. Lycopene protects pancreatic acinar cells against severe acute pancreatitis by abating the oxidative stress through JNK pathway. Free Radic Res. 2015;49(2):151-163.

22. Rahman SH, Ammori BJ, Holmfield J, Larvin M, Mcmahon MJ. Intestinal hypoperfusion contributes to gut barrier failure in severe acute pancreatitis. J Gastrointest Surg. 2003;7(1):26-36.

23. Chen QJ, Yang ZY, Wang CY, et al. Hydroxyethyl starch resuscitation downregulate pro-inflammatory cytokines in the early phase of severe acute pancreatitis: A retrospective study. Exp Ther Med. 2016;12(5): 3213-3220.

24. Floyd RA. The role of 8-hydroxyguanine in carcinogenesis. Carcinogenesis. 1990;11(9):1447-1450.

25. Cheng KC, Cahill DS, Kasai H, Nishimura S, Loeb LA. 8-Hydroxyguanine, an abundant form of oxidative DNA damage, causes G----T and A----C substitutions. J Biol Chem. 1992;267(1):166-172.

26. Feig DI, Reid TM, Loeb LA. Reactive oxygen species in tumorigenesis. Cancer Res. 1994;54(7 Suppl):1890s-1894s.

27. Zhang Z, Wang X, Cheng S, et al. Reactive oxygen species mediate arsenic induced cell transformation and tumorigenesis through $\mathrm{Wnt} / \beta$ catenin pathway in human colorectal adenocarcinoma DLD1 cells. Toxicol Appl Pharmacol. 2011;256(2):114-121.

28. Aikawa R, Komuro I, Yamazaki T, et al. Oxidative stress activates extracellular signal-regulated kinases through Src and Ras in cultured cardiac myocytes of neonatal rats. J Clin Invest. 1997;100(7):1813-1821.

29. Duracková Z. Some current insights into oxidative stress. Physiol Res. 2010;59(4):459-469. 
30. Wu R, Feng J, Yang Y, et al. Significance of Serum Total Oxidant/ Antioxidant Status in Patients with Colorectal Cancer. PLoS One. 2017;12(1):e0170003.

31. Wang D, Feng JF, Zeng P, Yang YH, Luo J, Yang YW. Total oxidant/ antioxidant status in sera of patients with thyroid cancers. Endocr Relat Cancer. 2011;18(6):773-782.

32. Singh AK, Pandey P, Tewari M, Pandey HP, Gambhir IS, Shukla HS Free radicals hasten head and neck cancer risk: A study of total oxidant, total antioxidant, DNA damage, and histological grade. J Postgrad Med. 2016;62(2):96-101.

33. Ellidag HY, Eren E, Aydin O, et al. Ischemia modified albumin levels and oxidative stress in patients with bladder cancer. Asian Pac J Cancer Prev. 2013;14(5):2759-2763.

34. Lee JK, Edderkaoui M, Truong P, et al. NADPH oxidase promotes pancreatic cancer cell survival via inhibiting JAK2 dephosphorylation by tyrosine phosphatases. Gastroenterology. 2007;133(5):1637-1648.

35. Vaquero EC, Edderkaoui M, Pandol SJ, Gukovsky I, Gukovskaya AS. Reactive oxygen species produced by NAD(P)H oxidase inhibit apoptosis in pancreatic cancer cells. J Biol Chem. 2004;279(33): 34643-34654.
36. Johnson CD, Abu-Hilal M. Persistent organ failure during the first week as a marker of fatal outcome in acute pancreatitis. Gut. 2004; 53(9):1340-1344.

37. Cingi Yirün M, Ünal K, Altunsoy Şen N, Yirün O, Aydemir Ç, Göka E. Evaluation of Oxidative Stress in Bipolar Disorder in terms of Total Oxidant Status, Total Antioxidant Status, and Oxidative Stress Index. Noro Psikiyatr Ars. 2016;53(3):194-198.

38. Yücel H, Türkdoğan KA, Zorlu A, Aydın H, Kurt R, Y1lmaz MB. Association between oxidative stress index and post-CPR early mortality in cardiac arrest patients: A prospective observational study. Anatol J Cardiol. 2015;15(9):737-743.

39. Supinski GS, Murphy MP, Callahan LA. MitoQ administration prevents endotoxin-induced cardiac dysfunction. Am J Physiol Regul Integr Comp Physiol. 2009;297(4):R1095-R1102.

40. Leeflang MM, Moons KG, Reitsma JB, Zwinderman AH. Bias in sensitivity and specificity caused by data-driven selection of optimal cutoff values: mechanisms, magnitude, and solutions. Clin Chem. 2008; 54(4):729-737.

\section{Publish your work in this journal}

OncoTargets and Therapy is an international, peer-reviewed, open access journal focusing on the pathological basis of all cancers, potential targets for therapy and treatment protocols employed to improve the management of cancer patients. The journal also focuses on the impact of management programs and new therapeutic agents and protocols on

\section{Dovepress}

patient perspectives such as quality of life, adherence and satisfaction. The manuscript management system is completely online and includes a very quick and fair peer-review system, which is all easy to use. Visit http://www.dovepress.com/testimonials.php to read real quotes from published authors.

\footnotetext{
Submit your manuscript here: http://www.dovepress.com/oncotargets-and-therapy-journal
} 